\title{
A Proposed Instructional Theory for Number in Preschool
}

\author{
José Luis Cortina ${ }^{a}$ \\ Jana Visnovska ${ }^{\mathrm{b}}$ \\ Jesica Peña@c \\ Claudia Zúñiga®d \\ a Universidad Pedagógica Nacional, México \\ ${ }^{\mathrm{b}}$ The University of Queensland, Australia \\ ${ }^{\mathrm{c}}$ Secretaría de Educación Pública, México \\ ${ }^{\mathrm{d}}$ Independent Scholar, México
}

Received for publication on 28 Oct 2020. Accepted after review on 6 Sep. 2021. Designated editor: M. Mar Liñán García

\begin{abstract}
Background: research has revealed that young children's development of early number concepts is critical for their long term success. Students who are more skilful with small numbers are much more likely to perform well in mathematics five and even more years after they leave preschool. Objectives: to develop an instructional theory for number in preschool, which is intended to be a resource with the potential for informing and guiding preschool teachers in supporting their students' development of early number concepts. Design: a preliminary version of an instructional theory was formulated and then tested in a classroom setting. Context and participants: a classroom design experiment was conducted in a public preschool classroom with 22 five-year-old students. Data collection and analysis: The research team assumed the role of a classroom teacher and used a preliminary version of the instructional theory to support the mathematical learning in class during 21 instructional sessions. This work analysed how participation and learning evolved. The analysis was used to assess the suitability of the instructional theory as a teaching resource and adjust it. Results: the results of the classroom design experiment indicate that the proposed instructional theory can be a useful resource for preschool teachers. Conclusions: the developed resource can help preschool teachers enhance their pupils' opportunities for long-term educational success in mathematics.
\end{abstract}

Keywords: Preschool mathematics; Preschool number; Teaching resources; Design research; Instructional design.

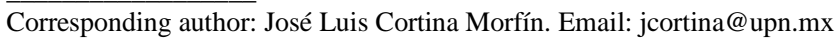




\section{Uma proposta de teoria instructional para número na pré-escola}

\section{RESUMO}

Contexto: As pesquisas revelam que o desenvolvimento de conceitos iniciais de números em crianças pequenas é fundamental para seu sucesso a longo prazo. Os alunos que são mais adeptos a números pequenos têm muito mais probabilidade de se sair bem em matemática cinco ou mais anos, depois de concluírem a pré-escola. Objetivos: desenvolver uma teoria instrucional para número na pré-escola, que pretende ser um recurso com potencial para informar e orientar os professores de préescola no apoio ao desenvolvimento de conceitos iniciais de número em seus alunos. Design: uma versão preliminar da teoria instrucional foi formulada e depois testada em sala de aula. Ambiente e participantes: um experimento de design de sala de aula foi realizado em uma classe de pré-escola de uma escola pública, com 22 alunos de cinco anos de idade. Coleta e análise de dados: a equipe de pesquisa assumiu o papel de professora de sala de aula e utilizou uma versão preliminar da teoria instrucional para apoiar a aprendizagem matemática em sala de aula durante 21 sessões de instrução. Este trabalho analisou como a participação e a aprendizagem evoluíram. A análise foi utilizada para avaliar a adequação da teoria instrucional como recurso didático e ajustála. Resultados: os resultados do experimento de design de sala de aula indicam que a teoria instrucional proposta pode ser um recurso útil para professores de pré-escola. Conclusões: o recurso desenvolvido pode ajudar os professores da pré-escola a aumentar as oportunidades de seus alunos para o sucesso educacional de longo prazo em matemática.

Palavras-chave: Matemática pré-escolar; Número da pré-escola; Recursos de ensino; Pesquisa em design; Design Instrucional.

\section{INTRODUCTION}

A significant body of literature shows that preschool students' understanding of number is critical (Duncan et al., 2007; Geary et al., 2013; Jordan et al., 2009; Nguyen et al., 2016). This research has revealed that young children familiar and skilful with small numbers are much more likely to perform well in mathematics five and even more years after they leave preschool. Conversely, it has also revealed that those children whose familiarity and skills are limited are significantly less likely to succeed in school. This research is particularly important for educational systems such as the Mexican, where most students do poorly or very poorly in mathematics national and international assessments (Instituto Nacional para la Evaluación de la Educación, 2018; Organisation for Economic Co-operation and Development, 2013). It strongly supports considering that successful efforts for 
comprehensive improvement in mathematics learning would have to involve improving mathematics teaching in preschool.

The study reported in this paper attempts to contribute to the understanding of how instructional resources may support teachers in enhancing their pupils' opportunities to develop early number understanding. We report the results from a 5-month classroom design experiment (see, e.g., Cobb et al., 2003a). In 2017, we tested and further developed an instructional sequence, grounded in an instructional theory, meant to inform and guide preschool teachers on supporting their students' development of relatively sophisticated ways of reasoning about number patterns and partitions. To this end, we recrafted the patterns and partitioning instructional sequence (PPIS), originally proposed by McClain and Cobb (1999), and assessed it as a teaching resource (Visnovska \& Cortina, 2021) in a preschool classroom with five-yearold students ${ }^{1}$.

Our goal was to investigate what adjustments need to be made to the original sequence and its underlying instructional rationale (Gravemeijer, 1994) to make it a useful teaching resource in under-resourced preschool classrooms. In this paper, we report on an analysis of 21 instructional sessions implemented over five months. The analysis focuses on the collective ways of participating in a preschool classroom, as the instructional sequence was used to inform and guide instruction. The analysis was conducted with the aim of empirically grounding the formulation of an instructional theory for number in preschool.

\section{THE PATTERNS AND PARTITIONS INSTRUCTIONAL SEQUENCE}

The PPIS, as originally formulated by McClain and Cobb (1999), is aimed at being a resource for teachers to generate opportunities for their students to conceptually construct patterns (finger patterns and spatial patterns) and partitions of collections of up to ten items and, in this way, favour the development of their pupils' early number concepts. In its development, the designers of this resource drew from their own research on the field of early

\footnotetext{
${ }^{1}$ Mexican public preschools typically offer three years of education. Students who are three years old (or about to be) are accepted in first grade. Students who are five years old (or about to be) are accepted in third grade. Pupils who conclude third grade of preschool transit to first grade of elementary school ('educación primaria')
} 
number learning (Steffe \& Cobb, 1988; Steffe et al., 1983) and research on early number instructional design, conducted mostly at the Freudenthal Institute (e.g., Van den Brink, 1989)2 ${ }^{2}$.

The PPIS includes tasks aimed at helping teachers in supporting their students to explore finger patterns, spatial patterns, and partitioning and recomposing collections. It is expected that, when being successful, teachers will be duly supporting their pupils' development of ways to solve arithmetic tasks involving quantities of ten or less.

By and large, the development of the number conceptions that the PPIS aims at by helping teachers to support their students is analogous to the competencies that have been recognised as being desirable in young pupils (Clements, 2004) and strongly correlated with advantageous and long-term mathematical achievement. According to Jordan and her colleagues (Jordan et al., 2009), in addition to grasping counting principles, these competencies include apprehending the value of small quantities immediately, making judgments about numbers and their magnitudes, and joining and separating sets. The PPIS can thus be a potentially valuable resource for teaching aimed at enhancing young children's opportunities for long-term educational success in mathematics.

It is important to point out that, although the PPIS was formulated with the idea that it could be used by teachers at the kindergarten level (five- and six-year-old students), it was developed as part of a classroom teaching experiment in first grade (six- and seven-year-old students). To our knowledge, its usefulness as a teaching resource had not been systematically explored in a classroom with younger students, particularly with students whose opportunities to engage in activities that afford rich mathematical learning is typically limited, both in their classrooms and out of school.

To better illustrate this point, it is worth highlighting that the first-grade students who participated in the classroom design experiment that served to develop the PPIS had all seemed to have previously developed elementary, albeit essential, numerical abilities (Gelman \& Gallistel, 1978; Sarama \&

\footnotetext{
${ }^{2}$ It is worth mentioning that the PPIS has many similarities with the instructional designs developed by the 'TAL Team' at the Freudenthal Institute (Van den HeuvelPanhuizen, 2001). However, it also has significant differences, such as introducing models for supporting non-counting based calculations (like the ten-frame and the rekenrek) much earlier in instruction.
} 
Clements, 2009), such as counting with cardinality up to ten, and being able to discriminate and correctly identify the meaning of written numerals, from 0 to 10 (see Whitenack, 1995). By contrast, very few of the children in the classroom in which we planned to work seemed to have developed these skills.

Six weeks before beginning the instructional sessions, we interviewed the 22 students that were to participate in the classroom design experiment ${ }^{3}$. Briefly, we identified that only four of the children seemed to have already developed the ability to count with cardinality up to ten. These students could also correctly read numerals up to 10 . Of the remaining pupils, eleven could canonically enumerate, with one-to-one correspondence, collections of up to seven or eight items, but without seeming to attribute to their enumeration a cardinal value. Three more could only canonically enumerate collections of up to five or six items, also without cardinality. The children in these two latter groups could correctly read several single-digit numerals. Finally, the conceptions about numbers of the remaining four students appeared to be rather limited. Not only did they not maintain a one-to-one correspondence when enumerating, but they also could not say the word number sequence correctly beyond three. In addition, they only correctly identified the names of one or two of the single-digit numerals.

As can be noticed, as a whole, the children that were going to participate in our study significantly lagged in their understanding of number, compared to the students that participated in the classroom design experiment that served to develop the PPIS. This, however, did not make the classroom in which we were going to work atypical in the Mexican educational system. On the contrary, based on our experience as researchers and teachers working in public schools, the students' overall performance was rather similar to what we had observed in many other classrooms of five-year-olds.

\section{AN EMERGING INSTRUCTIONAL THEORY FOR NUMBER IN PRESCHOOL}

Our goal in conducting the study was to develop an instructional theory (Stephan \& Akyuz, 2012) that would be a useful resource in informing and guiding successful mathematics teaching, in preschool classrooms attended by students whose prior knowledge of number would be similar to what we documented in the briefly described interviews. More specifically, it would

\footnotetext{
${ }^{3}$ The results of this assessment are published in Cortina and Peña (2018).
} 
inform and guide teaching aimed at supporting students' development of the rather sophisticated number understandings specified in the PPIS. To this end, we designed a teaching resource that included a conjectured sequence of mathematical learning goals and their justifications (Pepin, 2018), as well as the instructional means that could help teachers to pursue them. These means included instructional activities, manipulatives and concrete models, and aspects of a classroom ecology to be constituted, such as classroom norms (Lampert, 2001; Yackel \& Cobb, 1996).

We tested the designed resource by using it in supporting a classroom of preschool children to develop early number concepts. We analysed our teaching effort, focusing on collective participation ${ }^{4}$ and learning in the classroom. Finally, we used the results of our analysis to adjust the teaching resource further and formulate it as an instructional theory for number in preschool.

\section{The instructional design approach}

In our study, we used the same instructional design approach that grounded the formulation of the PPIS (McClain \& Cobb, 1999), the theory of Realistic Mathematics Education (RME). The roots of RME are based on the idea of mathematics as a human activity (Freudenthal, 1973). In Freudenthal's view, students should be given the opportunity to reinvent mathematics by organising or mathematising either real-world situations or mathematical relationships and processes that have substance for them. In developing this position, Freudenthal emphasised that the material students are to mathematise should be real for them. It is for this reason that the approach is called Realistic Mathematics Education (see Cobb et al., 2008).

A key objective of RME is the development of domain-specific instructional theories. As explained by Cobb et al. (2003b), instructional theories of this type comprise a substantiated learning pathway, and the demonstrated means of supporting that learning (see also Gravemeijer, 1994). They are meant to offer teachers an empirically grounded rationale on why specific learning goals are worth pursuing, sequentially, and how they can be successfully pursued by engaging students in a set of instructional activities, with multiple means of support (Cobb et al., 2008). The development of these instructional theories is never considered complete. Instead, they are

\footnotetext{
${ }^{4}$ The ways in which participation evolved in the classroom are only marginally addressed in this paper. For a more complete account see Peña (2018) and Peña et al. (2018).
} 
susceptible to continual improvements as they are tested by researchers and teachers in increasingly more and diverse classroom settings. However, as they become subject to this refinement process, these instructional theories are also expected to become increasingly stable.

Building on McClain and Cobb's (1999) PPIS, we formulated a provisional version of the instructional theory for number in preschool (Gravemeijer et al., 2003). Central to this endeavour was adding a component to the original conjectured learning pathway, in which children like those we had interviewed would have to be supported to first develop the elementary number understandings that they would need, to make it possible to successfully help them engage in the instructional activities included in the PPIS later on.

Given that our provisional version of the instructional theory showed to be a viable teaching resource in the classroom design experiment - as we will explain further in the analysis - we now describe it in detail. In the final part of this paper, we will address the minor but relevant modifications we made to it based on the results of the classroom design experiment.

\section{A provisional instructional theory}

The instructional theory that we formulated aims at being a resource that can successfully guide and aid teachers in supporting their students' attainment of two key learning goals. The first is the development of elementary numerical abilities that would allow a child to engage in the classroom activities proposed in the PPIS productively. The second is the development of relatively sophisticated ways of reasoning about patterns and partitioning with numbers up to ten.

To reach these goals, we formulated a conjectured learning pathway in which we divided and sequenced the pursue of the two main learning goals, aiming to first support the development students' competencies with numbers up to five, and then continue with numbers up to ten. The conjectured learning pathway entails four major instructional phases, each of which includes several specific learning objectives (see Table 1).

\section{Table 1}

A conjectured learning pathway for number in preschool

$\begin{gathered}\text { Instructional } \\ \text { phase }\end{gathered}$
Overarching goal




\begin{tabular}{|c|c|c|}
\hline 1 & $\begin{array}{l}\text { Support students' } \\
\text { development of the } \\
\text { essential number } \\
\text { understandings up to five }\end{array}$ & $\begin{array}{l}\text { Master the number word } \\
\text { sequence } \\
\text { - Enumerate with one-to-one } \\
\text { correspondence } \\
\text { - Use fingers to represent } \\
\text { numbers } \\
\text { - Identify the names of written } \\
\text { numerals }\end{array}$ \\
\hline 2 & $\begin{array}{l}\text { Support students' } \\
\text { reasoning about patterns } \\
\text { and partitioning with } \\
\text { numbers up to five }\end{array}$ & $\begin{array}{l}\text { - Reason about spatial patterns } \\
\text { - Reason about finger patterns } \\
\text { - Reason about number partitions } \\
\text { in the ten-frame } \\
\text { - Subitize and reason about } \\
\text { spatial patterns in the ten-frame } \\
\text { - Reason about how to solve } \\
\text { arithmetic problems }\end{array}$ \\
\hline 3 & $\begin{array}{l}\text { Support the development } \\
\text { of students' essential } \\
\text { number understandings up } \\
\text { to ten }\end{array}$ & $\begin{array}{l}\text { Master the number word } \\
\text { sequence } \\
\text { - Enumerate with one-to-one } \\
\text { correspondence } \\
\text { - Use fingers to represent } \\
\text { numbers } \\
\text { - Identify the names of written } \\
\text { numerals }\end{array}$ \\
\hline 4 & $\begin{array}{l}\text { Support students' } \\
\text { reasoning about patterns } \\
\text { and partitioning with } \\
\text { numbers up to ten }\end{array}$ & $\begin{array}{l}\text { - Reason about finger patterns } \\
\text { - Subitize and reason about } \\
\text { spatial patterns in the ten-frame } \\
\text { - Reason about number partitions } \\
\text { in the rekenrek } \\
\text { - Reason about arithmetic } \\
\text { problems }\end{array}$ \\
\hline
\end{tabular}

\section{Phase one, essential number understandings up to five}

With the results of the students' interviews in mind, we revised the PPIS and conjectured that in the classroom we were going to work, a teacher's prospects of successfully favouring her pupils' development of early number concepts would be widely enhanced if she first supported all her students to develop four basic numerical abilities. These were: (1) mastering the number word sequence, (2) enumerating collections, (3) using their fingers to show numbers, and (4) identifying the names of written numerals. Thus, we 
conjectured that in our role as classroom teachers, if we first supported the development of these abilities in our students, later, it would be possible to successfully help them engage in the patterns and partitioning instructional activities.

In Phase 1 of the conjectured learning pathway, supporting the development of each of the abilities became a learning objective. For the abilities that some students had previously developed, we considered that Phase 1 would provide them with an opportunity to strengthen those.

Building on the work of other researchers and our instructional expertise, we designed activities that could help us, in our role as classroom teachers, to support the development of each of these abilities in our pupils. To support students to master the number word sequence, we relied on Wright and his colleagues' (Wright et al., 2006) study. Their proposed activities are aimed at helping students to master saying the number word sequence forward, backwards, and immediately before or after a given number word. In addition to these activities, we included the singing of counting songs.

As for the objective of supporting students to enumerate collections, we designed an activity set in a narrative about a candy factory. Using a large quantity of Unifix cubes, students would be asked to make many sets of a given number (e.g., sets of four cubes). The sets would represent bags of candy. Building on the work by Siegler (2009) and Kamii and Housman (2000), we also included activities in which students would play a game board using a modified dice (see Figure 1).

\section{Figure 1}

A dice is modified so that instead of showing six dots in one of its faces, it shows none.

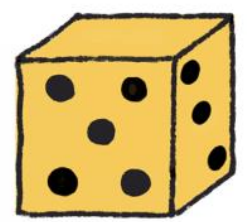

As for the objective of supporting all students to use their fingers to express quantities, we adapted a 'Simon says' activity proposed in the PPIS. It is worth mentioning that a central aspect of this objective was helping students develop the motor skills that would allow them to raise some of their fingers while lowering others easily. 
Finally, to identify the names of written numerals, we incorporated some of the tasks proposed by Wright and colleagues ${ }^{\circ}$ and designed a 'Lotería' game (i.e., a Bingo-like game), which is played with a board that has four written numbers on it $^{5}$.

\section{Phase two, patterns and partitioning with numbers up to five}

In this second phase of instruction, students would be supported to develop ways to conceptually construct patterns of small numbers, so that they would eventually come to establish how many items are in a set without counting them. In addition, a teacher would try to provide students with opportunities to generate partitionings of collections.

This phase entails five learning objectives (see Table 1), four of which are associated with a particular instructional activity included in the PPIS. The first objective consists of supporting students to reason about spatial patterns, using an instructional activity that involves subitising. Students are shown a collection of items for a short time, asked to say how many items they saw, and to explain how is it that they knew how many they were.

The second objective consists of supporting students to reason about finger patterns. The activity involves a "Simon says" game, in which the teacher asks students to show a specific number of fingers using both hands.

The third objective consists of supporting students to reason about spatial patterns in the ten-frame, which also involves subitising. Students are shown a collection of items in a single ten-frame for a short time, asked to say how many items they saw, and to explain how they knew how many they were.

The fourth objective consists of supporting students to reason about number partitions in the ten-frame, in the context of an activity in which students are asked to determine various ways a given number of items can be distributed into two locations. This instructional activity includes a narrative about a double-deck watermelon stand (see Figure 2).

\footnotetext{
${ }^{5}$ A detailed description of all the activities is included in Peña (2018).
} 


\section{Figure 2}

Image of the model of a watermelon stand used by the teacher.

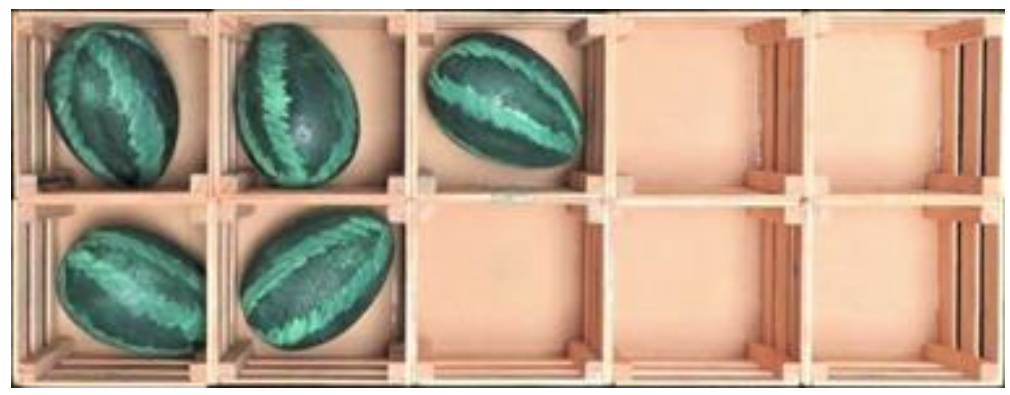

The fifth and final objective consists of supporting students' reasoning about the solution to simple arithmetic problems. One such problem might involve a narrative about a horse stable. Students could be asked to determine how many horses would be if three were inside the stable and two outside.

\section{Phase three, essential number understandings up to ten}

The purpose of this third phase of instruction would be to extend the scope of the students' essential abilities so that they reach numbers up to ten. Hence, the same four learning objectives of Phase 1 would be pursued, but now with numbers up to ten: (1) mastering the number word sequence, (2) enumerating collections, (3) using their fingers to show numbers, and (4) identifying the names of written numerals. The proposed activities are similar, although necessarily more complex. For instance, the 'Lotería' game now uses a board with nine numerals, which is now played with two dice.

\section{Phase four, patterns and partitioning with numbers up to ten}

This final phase of instruction entails four learning objectives (see Table 1), three of which are associated with particular kinds of instructional activity included in the PPIS. The first objective consists of supporting students to reason about finger patterns in a similar activity to the one explained in Phase 1. The second involves supporting pupils to become capable of subitising with ease in ten-frame, and reason about spatial patterns. Importantly, opportunities would now be provided to students to use 'five' and 'ten' as referents when discussing the patterns in whole-class conversations.

The third objective consists of supporting students to reason about number partitions in the rekenrek. Like with the ten-frame, students would be asked to determine various ways a given number of items might be distributed 
into two locations. This instructional activity includes a narrative about a double-deck tour bus.

The fourth and final objective involves supporting students' reasoning about how to solve simple arithmetic problems. These could be set in the same context of the tour bus and include determining the number of tourists riding on the bus, as some get on or off it. For instance: "There were two tourists riding on the bus. At the next stop, seven tourists get on. How many tourists are now riding on the bus?"

\section{Other means of support}

In describing each phase of the proposed instructional theory, we have already mentioned many of the instructional resources it includes. We have referred to specific activities and tasks, as well as to particular ways of using manipulatives such as Unifix cubes, ten-frames, and rekenreks. However, the span of the means of support we propose teachers to use goes beyond instructional activities, symbols and tools. These means also include establishing in the classroom a particular kind of activity system (Cobb et al., 2008).

\section{THE CLASSROOM CONTEXT}

The classroom design experiment that served to test the provisional instructional theory for number in preschool was implemented in a public preschool that is located in Xochimilco, an old town that is now part of Mexico City. The school operated an afternoon shift, from 2:30 to 5:30 p.m. It served a total of ninety students, all of whom were the children of very low-income families living in the area. It had one first-grade, one second-grade, and two third-grade classrooms.

The experiment was conducted in one of the third-grade classrooms. As we previously mentioned, it consisted of 21 instructional sessions that were implemented over five months. Typically, there would be two sessions per week. However, instruction was interrupted for the two-week Spring break and several school events, such as the Mothers' Day festival.

All the instructional sessions were conducted by the third author, who, then, had five years of teaching experience, all in the school where the design experiment took place. During the implementation of the design experiment, she was not a regular member of the school staff, since she was enrolled on a master's programme, with paid leave. In addition to the third author, the regular 
classroom teacher was present in all the instructional sessions, and keenly supported us in whatever was needed.

The third author also conducted pre- and post-interviews to assess all the students' understanding of numbers before and after the instruction. The interviews were conducted in small groups of four children or less, and were video recorded.

Once the instructional sessions began (in January 2017), data collection continued with the class observations recorded through video and a teacher log. Between each instructional session, the first and third authors held planning meetings when they analysed classroom developments and considered the suitability of the local instructional theory as a resource for making sense of and guiding the teaching in which they, as a team, were involved. They too agreed on how to proceed with instruction. Both participants kept notes of each of these meetings.

\section{METHOD}

The main purpose of implementing the classroom design experiment was to assess the suitability of the provisional instructional theory. To do so, we followed the methodology proposed by Gravemeijer and Cobb (2006). When planning each of the instructional sessions, we used the conjectured learning pathway as our main guide. After the session concluded, the third author analysed the videorecording and her notes, focusing on the different ways in which the students had participated in the activities. During the planning briefings, the first and third authors discussed to what extent progress had been made. We took as evidence of progress when an increasing number of students appeared to be fully engaging in the instructional activities for an increasing amount of time. We focused particularly on the students whose performance appeared to lag the most when compared to the rest of the group.

We considered that a learning objective had been accomplished when the great majority of the students (if not all) would readily engage in the instructional activities associated with this objective and participate in it with proficiency and ease. Below, in the analysis section of this paper, we offer specific examples.

Following Gravemeijer and Cobb (2006), once the instructional sessions were over, we conducted a retrospective analysis. In it, with the benefit of hindsight, we assessed the viability of the instructional judgments and 
decisions made during the intervention, and the considerations on which they were based. We did this by analysing the full body of data collected, including the video recordings, the teacher's log, and the two sets of notes. In this process, we sought evidence that would indicate that the ongoing considerations we formulated about the collective learning that was taking place in the classroom during the instructional sessions were misguided or unfitting ${ }^{6}$.

\section{ASSESSING THE SUITABILITY OF THE INSTRUCTIONAL THEORY}

The analysis of the classroom design experiment indicated that, overall, the provisional instructional theory was viable. As we explain in more detail next, it was possible to reach the planned learning objectives sequentially (see Table 1). The proposed instructional activities, as well as the other means of support, proved to be helpful resources for supporting the students' development of essential number understandings, up to five, as specified in Phase 1. Consistent with our conjecture, this accomplishment seemed critical in subsequently allowing us to successfully support the class in engaging in the instructional activities of Phase 2. The objectives of Phase 3 were also met, and, generally speaking, this was also the case with the objectives of Phase 4.

\section{Phase 1}

We were able to support the students in reaching the learning objectives of Phase 1 during the first five instructional sessions. In each of them, the classroom teacher ${ }^{7}$ tried to engage the class in six or seven instructional activities. For instance, in Session 3, she first played a game of saying the number word sequence in all its forms (forward, backwards, the number that comes next, and the number that comes before). Then, students used Unifix cubes to make packages of four candies. Next, she used printed cards and asked students to say the name of the number she was showing them and explain how they knew it. After that, the class sang a counting song, and then, they played the 'Lotería' game. The final activity of that day was using fingers to show quantities.

\footnotetext{
${ }^{6}$ A full explanation of how this process is accomplished can be found in Cobb and Whitenack (1996).

${ }^{7}$ From here on we use the term 'the classroom teacher' to refer to the member of the team who was present in the classroom, and mainly in charge of instruction. This being the third author.
} 
The first learning objective to be achieved was mastering the number word sequence. We conjectured that the classroom teacher was finally successful in supporting this achievement during Session 4, when it became apparent that all students readily engaged in the activity of saying the number word sequence and participated in it with ease. This was so, although the classroom teacher made sure that the students who had previously struggled the most were actively participating. Our retrospective analysis corroborated this conjecture, as we found no further instances in which a student struggled to say the number word sequence.

The other three objectives were reached in Session 5. In the case of using fingers to represent numbers, although several of the students still struggled with motor skills, they were all able to show the number of fingers that the teacher asked, using either of their hands. As for identifying the meaning of written numerals, in the 'Lotería' game, all the students seemed to play it with ease. In addition, the teacher asked the student who had previously struggled the most when playing the game to be the person who read the cards and call the numbers, which she did correctly and without help. Finally, for enumerating with one-to-one correspondence, all the students seemed to be able to play the game board with ease. They all seemed to correctly enumerate the dots in the dice, as well as the squares they needed to advance with their tiles. Once more, the retrospective analysis indicated that our considerations at the time were adequate.

\section{Phase 2}

This phase entailed testing a critical conjecture: by having reached the learning objectives specified for Phase 1, it would be possible to successfully support the class to productively engage in the instructional activities specified in the PPIS, with numbers up to five. As we explain next, this conjecture proved to be viable.

The whole of Session 6 was spent in the partitioning instructional activity, set in the context of a watermelon stall. The classroom teacher first had a conversation with the whole class in which she asked the students if they knew markets and about the things that are sold there. Next, she told the class about a friend of hers, Doña Esperanza, who sells watermelons in a stall with five boxes on top and five on the bottom. She then showed them a model of the stall, structured as a ten-frame (see Figure 2), which was placed in front of the class for everyone to see. She also provided every student with a ten-frame and five plastic chips so that they could explore how to organise the stall individually. 
Once the classroom teacher considered that everyone had understood the situation, she asked the students to think about different ways in which Doña Esperanza might be able to arrange five watermelons on her stall. Students explored different ways in their individual ten-frames and then proposed them to the teacher. She used the board to keep a record of students' solutions, specifying how many watermelons were in the top deck and how many on the bottom one (see Figure 3).

\section{Figure 3}

The record kept by the teacher about the distribution of the watermelons in the two decks.

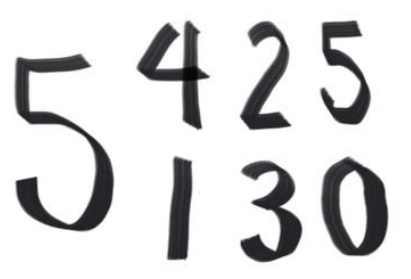

The activity seemed to be rather challenging for all the students. It was noticeable that when the teacher asked for other arrangements, students would often propose one that had already been used, sometimes more than once. Still, it seemed that all the students understood what the activity was about, that they could follow the explanations given and contribute to the conversation. They, too, seem to be making sense of the record that was kept on the board, which used written numerals (see Figure 3). In general, the way the children participated in this class suggested we had been successful in supporting their development of the number understandings necessary to initially engage in the watermelon activity.

In the ensuing session (Session 7), the classroom teacher introduced the students to the activities aimed at supporting reasoning about spatial patterns and about finger patterns. By and large, the students participated in a way akin to how they had done in the partitioning activity, the previous session. Although the new activities were noticeably challenging for the children, it seemed that all understood what each activity was about and could meaningfully participate in them.

It took the classroom teacher six sessions to support the class to reach the learning objectives of Phase 2 (Sessions 6 to 11). In session 9, we noticed 
an important shift in the way students reasoned about number partitions in the stall. In proposing different ways of arranging the quantities of watermelons, their attention became clearly focused on the record that was kept on the board, instead of on the stall itself. The activity then became noticeably less challenging for the class. Even the students who initially struggled the most were now able to readily propose new ways of partitioning the quantities of watermelons, and also to notice when all the options for partitioning a certain quantity had been exhausted.

In the case of reasoning about finger patterns, in Session 10, it became apparent that the activity no longer represented a challenge for the class. Not only did all the students correctly show the number of fingers indicated by the classroom teacher, but they could also propose other patterns for showing them and readily recognise that the total amount was the same. For instance, a student who showed four fingers by raising three fingers in one hand and one in the other could change her way to two fingers in each hand. She could also recognise that a classmate who raised four fingers in one hand and none in the other had also shown four fingers.

In Session 11, it became apparent that all the students could correctly subitise spatial patterns of up to five items and explain their reasoning. They could likewise subitise patterns in the ten-frame. In that session, students could also solve simple arithmetic problems relying on their developed understandings of number patterns and partitions.

The problems that the classroom teacher used in that session were about horses that lived in a stable. Using a cardboard box and toy horses, the teacher created a model of the situation. In one of the problems, she showed three horses to the students and told them that they were outside of the stable. Then she told them that there was one more horse inside, and asked them to think about how many horses they were in total. The following conversation illustrates the way students reasoned about these problems:

Aurora ${ }^{8}$ : Four.

Marcos: Five.

Teacher (to Marcos): Why do you think there are five?

${ }^{8}$ All students' names are pseudonyms. 
Marcos: Because three were outside and one was inside. They are four!

This excerpt illustrates how students reasoned about the problems without resorting to counting by ones. Instead, they all seemed to make use of their recently developed understandings of number patterns and partitions. It is noticeable that when questioned by the teacher, Marcos seemed to recognise a number pattern and used it to make sense of the situation: that three and one would make four.

Once we considered that all students in the class looked able to participate in activities that involved solving arithmetic problems by reasoning about number patterns and partitions, we regarded that we had successfully supported the students to meet the learning objectives of Phase 2 (see Table 1). In this case, also, the retrospective analysis indicated that our considerations at the time were adequate. In particular, during the retrospective analysis of Phase 4 , we found no instances in which someone struggled in situations that involved generating patterns or partitioning quantities involving five items or less.

It is noteworthy that the achievement of the learning objectives of Phase 2 served to corroborate further the viability of the critical conjecture mentioned before: by having reached the learning objectives specified for Phase 1, it would be possible to successfully support the class to engage in patterns and partitioning instructional activities productively.

\section{Phase 3}

The most significant modification we made to the provisional instructional theory concerns this phase. In the briefing between sessions seven and eight, the classroom teacher considered that it would be possible to dedicate part of the upcoming instructional sessions to pursue the learning objectives of Phase 3 (see Table 1), despite not having yet accomplished the goals of Phase 2. It was then considered that it would be worthwhile to explore this possibility, so in Session 8, the teacher started to use the final 15 to 20 minutes of each session to work in the instructional activities of Phase 3. Consequently, Sessions 8 to 11 were used to pursue learning objectives of Phases 2 and 3 of the provisional instructional theory.

The analysis of the classroom design experiment indicated that this modification was viable. In the briefing after Session 11, we considered that we had successfully supported the class to reach the learning objectives of Phase 3 , which meant that students had extended their essential number understandings to work with numbers up to ten. Consequently, it seemed that 
all students could say the number word sequence up to ten, forward and backwards. They could also say the number immediately before or after a given number word. In addition, they could correctly read numerals up to ten and enumerate collections of up to ten items. Finally, all students seemed capable of correctly showing with their fingers numbers up to ten.

Our considerations about having met the objectives of Phase 3 by Session 11 also appeared adequate once the retrospective analysis was completed. Most noticeably, we were successful in supporting the class to engage in the instructional activities of Phase 4 productively, as we explain next.

\section{Phase 4}

This phase took the longest number of sessions, ten in total (Sessions 12 to 21), from March 9 to May 11. During this period, spring break, three school festivals (Spring, Children's, and Mothers' Days), and two other special school events happened. There was also an increase in students' absenteeism. The average attendance during these ten sessions was 14.5 students. Only one boy attended all the instructional sessions in this phase, and there was a group of eight children who missed more than half of them. Despite these contingencies, it seemed that we were successful in supporting most of the students in developing ways of reasoning that were consistent with the learning objectives of Phase 4.

The first learning objective of this phase, in which we successfully supported the students, was reasoning about finger patterns. We conjectured this happened during Session 14, when it became apparent that all the attending students readily showed the number of fingers indicated by the teacher. We observed that some were using 'five' as a referent for their patterns. For instance, when asked to show eight fingers, Sabina showed five in one hand and three on the other. When the teacher asked her how she knew that she was showing eight fingers, she answered: "I have five (gesturing with her opened right hand), and I have three (showing three fingers in her left hand)."

Other students used 'ten' as a referent. For instance, in the same task, Raul used the same pattern as Sabina but explained it this way: 'because two are missing' (apparently, meaning that if he showed two more fingers, he would be showing a total of ten).

The second learning objective of this phase in which we successfully supported the students was subitising and reasoning about spatial patterns in the ten-frame. We conjectured this happened in Session 16, when all the 
attending students readily recognised the number of items that the teacher showed on the watermelon stall. Here too, some students used 'five' as a referent to explain how they had recognised the amount, and others used 'ten'.

After Session 20, we conjectured that we had been successful in supporting the students to accomplish the objective of reasoning about number partitions in the rekenrek. The class easily found all the ways in which a number of tourists could be distributed on the two decks of the tour bus, and did so by focusing mostly on the record that was kept on the board (see Figure 4).

\section{Figure 4}

The record kept by the teacher about the distribution of the tourists in the two of the tour bus.

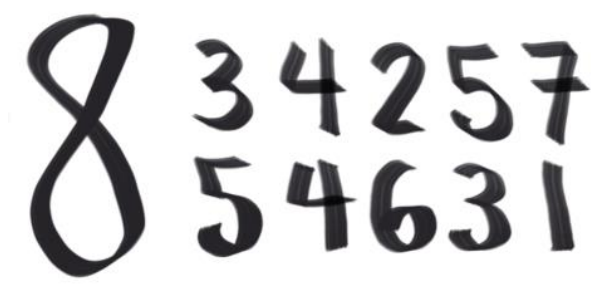

The fourth learning objective of this phase in which we successfully supported the students was reasoning about arithmetic problems. We conjectured that this happened in Session 21, when the classroom teacher presented students with problems about passengers getting on and off the tour bus. The following extract is representative of how students reasoned about these problems. It is about a situation in which students were told that a tour bus left a park with four tourists. Then it made a stop at a museum, without the bus driver noticing whether tourists got on or off. Finally, when arriving at the final destination, the bus driver noticed that there were ten tourists onboard. Students were asked to explain what happened at the museum.

Teacher: ... what happened at the museum?

Several children: They got on.

Teacher: Armando, what do you think?

Armando remains silent.

Teacher (to the whole class): How do you know they got on? 
Lupe: Six got on because six are missing for ten.

Teacher (to the whole class): Did you understand?

Hernan: Yes! Six are missing because there were four, and six are ten.

Teacher (to the whole class): Ten what?

Lupe: Passengers.

In this extract, both Lupe and Hernan seemed to reason about the problem drawing on their understandings of number patterns and partitions. It is noteworthy how both referred to the three quantities involved (4, 10 and 6) without seeming to resort to counting by ones.

It is worth mentioning that our considerations about having successfully supported the students to meet the objectives of Phase 4 also seemed adequate once the analysis of the post-interviews was completed.

\section{Post-interviews}

In the two weeks that followed Session 21, we interviewed 19 of the 22 students who participated in the pre-interviews, in small groups. We also postinterviewed a student who had not participated in the pre-interviews because she joined the class in Session 5. As part of the post-interviews ${ }^{9}$, we presented students with problems grounded on a narrative about ducklings swimming in a lake. Some of the ducklings were visible to the students in some of these problems, and some were not. In others, none of the ducklings were visible. Three of these problems involved five or fewer ducklings, and three involved ten or fewer.

Fourteen students reasoned about the problems seeming to draw on

their understandings about number patterns and partitions. The following extract is representative of how these students reasoned:

Teacher: There are ten ducklings in total, and seven are outside (visible). How many are hidden under the water?

Juan (quickly answering): Three (showing three fingers).

Teacher: Why do you think they are three?

${ }^{9}$ A complete report of the post-interviews can be consulted in Author (2018). 
Juan: Because seven are outside. There are three under, because there are ten.

Similar to how the children reasoned in the previous excerpt, Juan immediately answered. Then, he alluded to the three quantities involved ( 7,3 and 10) without seeming to resort to counting by ones.

The answers given by five other students suggested that they could draw on their understanding of patterns and partitions to solve problems only when the number of elements involved was five or fewer. They seemed capable of correctly solving the other problems by counting by ones.

The remaining student apparently drew on her understanding of patterns and partitions to solve problems, when the quantities involved were small. The problems with numbers up to ten seemed significantly challenging for her, even when trying to solve them by counting by ones.

\section{DISCUSSION}

Our goal in this study was to assess the suitability of an instructional theory for number in preschool. To formulate it, we drew heavily on the work of McClain and Cobb (1999) and other researchers. The results of our analysis of the classroom design experiment support considering the proposed instructional theory useful. The conjectured learning pathway, together with the proposed instructional means, informed and guided our successful efforts to support all the students to develop the necessary number understandings to productively engage in activities that involved reasoning about patterns and partitioning with numbers up to five. It also informed and guided our efforts to support the great majority of the students to participate in activities that involved reasoning about patterns and partitioning with numbers up to ten.

Our findings suggest that the central conjecture included in the instructional theory, consisting of first supporting students to develop essential number understandings, such as those specified in Phases 1 and 3 (see Table 1), to make it possible to successfully engage them, later on, in patterning and partitioning activities, is viable. Our evidence comes from our analysis of the mathematical learning of the classroom community, particularly of how the classroom teacher was successful in supporting the students to engage in the instructional activities used in Phases 2 and 4.

The results of the classroom design experiment led us to make a minor albeit relevant revision to the conjectured learning pathway of the proposed 
instructional theory. It concerns the sequencing of phases 2 and 3. Our findings indicate that Phase 3 objectives need not be pursued, necessarily, only when those of Phase 2 have been reached, but that a teacher can pursue the objectives of both phases in tandem.

Our research findings, when contextualised within the body of literature we discuss at the beginning of this paper (Duncan et al., 2007; Geary et al., 2013; Jordan et al., 2009; Nguyen et al., 2016), support our proposed instructional theory as a valuable teaching resource. It can inform and guide preschool teachers who work in under-resourced classrooms -like those typical in the public-school systems of developing countries like Mexico- in the challenging endeavour of supporting their students' development of early number concepts. Consequently, the proposed instructional theory can be a resource that helps preschool teachers significantly enhance their pupils' opportunities for long-term educational success in mathematics.

\section{AUTHORS' CONTRIBUTIONS STATEMENTS}

JLC and JV conceptualised the study; JP conducted the study; JP and $\mathrm{CZ}$ collected the data; all authors analysed the data; JLC and CZ wrote the manuscript; JV revised the manuscript critically; all authors actively participated in the discussion of the results, and reviewed and approved the final version of the manuscript.

\section{DATA AVAILABILITY STATEMENT}

Data supporting the results of this study will be made available by the corresponding author, $[\mathrm{CZ}]$, upon reasonable request.

\section{REFERENCES}

Cobb, P., Confrey, J., diSessa, A., Lehrer, R., \& Schauble, L. (2003a). Design experiments in education research. Educational Researcher, 32(1), 913.

Cobb, P., McClain, K., \& Gravemeijer, K. (2003b). Learning about statistical covariation. Cognition and Instruction, 21, 1-78. 
Cobb, P., \& Whitenack, J. (1996). A method for conducting longitudinal analyses of classroom videorecordings and transcripts. Educational Studies in Mathematics, 30, 213-228.

Cobb, P., Zhao, Q., \& Visnovska, J. (2008). Learning from and adapting the theory of realistic mathematics education. Education et Didactique, 2(1), 55-73.

Cortina, J. L., \& Peña, J. (2018). Nociones numéricas de alumnos mexicanos de tercero de preescolar. Educación Matemática, 30(3), 103-123. https://doi.org/10.24844/EM3003.05

Duncan, G. J., Dowsett, C. J., Claessens, A., Magnuson, K., Huston, A. C., Klebanov, P., Pagani, L. S., Feinstein, L., Engel, M., Brooks-Gunn, J., Sexton, H., Duckworth, K., \& Japel, C. (2007). School readiness and later achievement. Developmental Psychology, 43(6). https://doi.org/10.1037/0012-1649.43.6.1428

Freudenthal, H. (1973). Mathematics as an educational task. Reidel.

Geary, D. C., Hoard, M. K., Nugent, L., \& Bailey, D. H. (2013). Adolescents' functional numeracy is predicted by their school entry number system knowledge. PLoS One, 8(1), 1-8.

https://doi.org/10.1371/journal.pone.0054651

Gelman, R., \& Gallistel, C. R. (1978). The child's understanding of number. Harvard University Press.

Gravemeijer, K. (1994). Developing realistic mathematics education. CD-B Press.

Gravemeijer, K., Bowers, J., \& Stephan, M. (2003). A hypothetical learning trajectory on measurement and flexible arithmetic. In M. Stephan, J. Bowers, P. Cobb, \& K. Gravemeijer (Eds.), Supporting students' development of measuring conceptions: Analyzing students' learning in social context (pp. 58-73).

Gravemeijer, K., \& Cobb, P. (2006). Design research from a learning design perspective. In J. van den Akker, K. Gravemeijer, S. McKenney, \& N. Nieveen (Eds.), Educational design research: The design, development and evaluation of programs, processes and products (pp. 45-85). Routledge. 
Instituto Nacional para la Evaluación de la Educación. (2018). Planea. Resultados nacionales. Sexto de primaria. Lenguaje y Comunicación. Matemáticas. Author.

Jordan, N. C., Kaplan, D., Ramineni, C., \& Locuniak, M. N. (2009). Early math matters: kindergarten number competence and later mathematics outcomes. Developmental Psychology, 45(3), 850-867. https://doi.org/10.1037/a0014939

Kamii, C., \& Housman, L. B. (2000). Young children reinvent arithmetic: Implications of Piaget's theory (2nd ed.). Teachers College Press.

Lampert, M. (2001). Teaching problems and the problems of teaching. Yale University Press.

McClain, K., \& Cobb, P. (1999). Supporting students' ways of reasoning about patterns and partitions. In J. V. Copley (Ed.), Mathematics in the early years. National Council of Teachers of Mathematics.

Nguyen, T., Watts, T. W., Duncan, G. J., Clements, D. H., Sarama, J. S., Wolfe, C., \& Spitler, M. E. (2016). Which preschool mathematics competencies are most predictive of fifth grade achievement? Early Childhood Research Quarterly, 36, 550-560. https://doi.org/10.1016/j.ecresq.2016.02.003

Organisation for Economic Co-operation and Development. (2013). PISA 2012 results: What students know and can do-student performance in mathematics, reading and science (Vol. 1). Author.

Peña, J. (2018). El sentido numérico en preescolar [Number sense in preeschool] [Unpublished master's thesis]. Universidad Pedagógica Nacional, Mexico City.

Peña, J., Cortina, J. L., \& Visnovska, J. (2018). What happened at Frida's museum? Teaching Children Mathematics, 25(3), 175-179. https://doi.org/10.5951/teacchilmath.25.3.0174

Pepin, B. (2018). Enhancing teacher learning with curriculum resources. In L. Fan, L. Trouche, C. Qi, S. Rezat, \& J. Visnovska (Eds.), Research on mathematics textbooks and teachers' resources: advances and issues (pp. 359-374). Springer.

Sarama, J., \& Clements, D. H. (2009). Early childhood mathematics education research: Learning trajectories for young children. Routledge. 
Siegler, R. S. (2009). Improving the numerical understanding of children from low-income families. Child Development Perspectives, 3(2), 118124.

Steffe, L. P., \& Cobb, P. (1988). Construction of arithmetical meanings and strategies. Springer.

Steffe, L. P., von Glasersfeld, E., Richards, J., \& Cobb, P. (1983). Children's counting types: Philosophy, theory, and application. Praeger Scientific.

Stephan, M., \& Akyuz, D. (2012). A proposed instructional theory for integer addition and subtraction. Journal for Research in Mathematics Education, 43(4), 428-464 https://doi.org/10.5951/jresematheduc.43.4.0428

Van den Brink, F. J. (1989). Realistisch rekenonderwijs aan jonge kinderen [Realistic mathematics education for young children]. Freudenthal Institute, Utrecht University.

Van den Heuvel-Panhuizen, M. (Ed.) (2001). Children learn mathematics: A learning-teaching trajectory with intermediate attainment targets for calculation with whole numbers in primary school. Freudenthal Institute, Utrecht University.

Visnovska, J., \& Cortina, J. L. (2021). On designing for mathematics teaching and how mathematics matters. Manuscript submitted for publication.

Whitenack, J. (1995). Modeling,mathematizing and mathematical learning as it is situated in the classroom microculture [Unpublished doctoral dissertation]. Vanderbilt University.

Wright, R. J., Martland, J., Stafford, A. K., \& Stanger, G. (2006). Teaching number. Advancing children's skills and strategies (2nd ed.). Paul Chapman.

Yackel, E., \& Cobb, P. (1996). Sociomathematical norms, argumentation, and autonomy in mathematics. Journal for Research in Mathematics Education, 27, 458-477. https://doi.org/10.2307/749877 